\title{
Dissecting Hematoma of Intracranial Internal Carotid Artery in an 8-year-old Girl
}

\author{
Roy H. Rhodes, Susan Phillips, Frances A. Booth, Kenneth G. Magnus
}

\begin{abstract}
Background: An 8-year-old girl had a minor fall without head trauma and she collapsed the following day while playing. She was awake but mute with focal neurologic signs when admitted to hospital. Radiologic imaging studies showed a progressive left cerebral infarct with left hemisphere vascular narrowing and beading. She died on the third hospital day. Methods: Autopsy including exploration of neck vessels and neuropathological examination was performed. Postmortem studies included immunostaining for immunoglobulins and fixed complement. Results: Subtotal subintimal dissections of both proximal supraclinoid internal carotid arteries were found microscopically. On the left, the subintimal dissection extended into the major branches of the left internal carotid artery as dissecting hematomas with a major compromise of the arterial lumina. Specific IgM deposition at the dissection sites was found. A literature review shows that subintimal dissection of the intracranial internal carotid artery or its branches occurs rarely, it is often fatal, and it is present in patients with a mean age of 17.5 years in cases studied pathologically. Trauma and physical exertion are the most common associated factors. Conclusions: Among the causes of ischemic stroke in young individuals, dissecting hematomas of the intracranial portions of the internal carotid artery system rank low. Few reported cases have identifiable pre-existing pathology. The pathogenesis of dissecting hematomas in this region is reviewed and expanded with speculation regarding relevant developmental, anatomical, flow stress and possibly humoral factors that are involved in the disruption of the arterial elastica and subsequent development and extension of a subintimal hematoma resulting in luminal closure and often death.
\end{abstract}

RÉSUMÉ: Hématome disséquant de la carotide interne intracrânienne chez une fillette de 8 ans. Introduction: Une fillette âgée de 8 ans a fait une chute mineure sans traumatisme crânien et elle s'est affaissée en jouant le lendemain. Elle était consciente mais ne pouvait parler et présentait des signes neurologiques focaux à l'admission. Des études radiologiques ont montré un infarctus cérébral gauche progressif avec un rétrécissement vasculaire à l'hémisphère gauche avec aspect en chapelet. Elle est décédée trois jours après son admission à l'hôpital. Méthodes: Une autopsie a été pratiquée, incluant une exploration des vaisseaux du cou et un examen neuropathologique incluant des études immunohistochimiques pour les immunoglobulines et la fixation du complément. Résultats: À la microscopie, on a constaté la présence de dissection sous-intimale subtotale de la portion supraclinoïdienne proximale des carotides internes. À gauche, la dissection sous-intimale s'étendait aux branches majeures de la carotide interne gauche sous forme d'hématomes disséquants qui compromettaient de façon importante la lumière artérielle. Des IgM spécifiques étaient présentes aux sites de dissection. Une revue de la littérature a montré que la dissection sous-intimale de la carotide interne intracrânienne ou de ses branches est rare, souvent fatale, et se retrouve chez des patients dont l'âge moyen est 17.5 ans dans les cas ayant subi un examen anatomopathologique. Un traumatisme ou l'activité physique intense sont les facteurs les plus souvent associés. Conclusions: Parmi les causes d'accident vasculaire cérébral chez les jeunes, l'hématome disséquant de la portion intracrânienne du système carotidien interne est une cause peu fréquente. Parmi les cas rapportés, peu ont une pathologie préexistante identifiable. Nous revoyons la pathogénèse des hématomes disséquants de cette région et nous discutons de facteurs du développement, de l'anatomie, des forces de cisaillement et de facteurs humoraux potentiels qui sont impliqués dans la perturbation de la couche élastique artérielle, et le développement subséquent et l'extension d'un hématome sous-intimal menant à l'oblitération luminale et souvent au décès.

Can. J. Neurol. Sci. 2001; 28: 357-364

Intracranial internal carotid artery system dissection is infrequently reported, its course is typically short and enigmatic, and it is often fatal. ${ }^{1-7}$ By comparison, magnetic resonance (MR) imaging has helped to establish arterial dissection in the extracranial internal carotid arteries as an important and more commonly survivable cause of cerebral infarction in adults. ${ }^{8-10}$ The mean age of patients with dissection in the neck vessels is 40 to 45 years, and the incidence is close to three cases per 100,000 population. ${ }^{11}$ Dissection through the medial layer in the neck vessels may be spontaneous, but there is often a history of trauma, including trivial head or neck trauma. ${ }^{5,6,9,12,13}$ Dissection of the intracranial vertebrobasilar system can be accompanied by rupture of the arterial wall with subarachnoid hemorrhage. ${ }^{14-16}$

Dissecting hematomas of the intracranial internal carotid artery system differ from neck vessel dissections by occurring in

From the Department of Pathology, (RHR, SP); Department of Pediatrics and Child Health, (FAB); Department of Radiology, (KGM); University of Manitoba, Health Sciences Centre, Winnipeg, Manitoba, Canada.

ReCEIVED DeCEMBER 11, 2000. ACCEPTED IN FINAL FORM June 27, 2001. Reprint requests to: R.H. Rhodes, Health Sciences Centre, Department of Pathology, MS-459, 820 Sherbrook Street, Winnipeg, MB R3A 1R9, Canada 
much younger patients and by having a plane of dissection that is subintimal and splits the internal elastic lamina from the media. Few of these patients have histologic evidence of a previous vasculopathy. ${ }^{17}$ Typically, these children and young adults have sudden onset of a lateralizing headache associated with trauma, including trivial head trauma with or without a delay, or with intense physical exertion and there is simultaneous or subsequent development of neurologic symptoms. The delay can be hours and sometimes days, ${ }^{18}$ and there is one report documenting a one year delay. ${ }^{19}$ There is a relatively rapid development of signs of cerebral ischemia with a progressive and fatal development of cerebral infarction in many instances. ${ }^{6,17}$ Naturally-occurring defects in the internal elastic lamina combined with hypertensive episodes have been linked to the initiation of the dissections of the anterior cerebral circulation. ${ }^{20}$ These dissections close the lumen and prevent blood flow, so they do not generally form a grossly-identifiable aneurysm, even though the artery can be expanded or beaded in imaging studies. ${ }^{6}$ Vertebrobasilar dissections may differ in that they can have significant disruption of the elastic layer and outer layers with demonstrable aneurysmal formation and subarachnoid hemorrhage. ${ }^{14-16}$ In the anterior circulation, a dissecting hematoma rather than aneurysmal formation is the focus of pathologic attention. Anatomic location, age differences and the physical properties of the intracranial internal carotid artery system under flow stress have not been accounted for in a unified theory of the mechanisms of intramural blood dissection. We present a case of an extensive dissecting hematoma of the intracranial internal carotid artery system in a child who had a minor fall and collapsed at play the following day. We review patients with similar findings and offer a contribution to the possible pathogenesis of the entity.

\section{CASE Report}

This 8-year-old, previously well, right-handed caucasian girl was reported to collapse suddenly and become unresponsive while playing with friends. No adult witnessed the event. Later history from her mother described a fall from a countertop without head trauma the previous day. During transfer to hospital, she opened her eyes and withdrew to pain. In the Emergency Department, she had a transient increase in systolic blood pressure to $140 \mathrm{~mm} \mathrm{Hg}$ associated with a heart rate of 50 to 60 beats per minute. Otherwise, vital signs were stable and she was afebrile. On initial neurological examination, she was awake, vocalizing but not verbalizing, had persistent eye deviation to the left, right upper motor neuron facial weakness, right extremity weakness and increased tone, right-sided hyperreflexia, right ankle clonus, and a right extensor plantar response with an equivocal left plantar response.

Her initial noninfused computed tomography scan showed subtle, decreased gray/white differentiation of the left cerebral hemisphere with small basal cisterns and cerebral ventricles, suggesting mild cerebral edema and a left-sided infarct. A repeat study 24 hours later showed progression of the lesion with some mass effect and petechial hemorrhages in the parenchyma of the left middle cerebral artery territory. MR imaging and MR angiography confirmed the presence of an almost total, acute, left-sided cerebral infarct involving the internal carotid artery distribution. The parenchyma of the left cerebral hemisphere was swollen resulting in mass effect on adjacent structures. Arterial calibre was reduced in the left supraclinoid internal carotid artery, A1 segment of the left anterior cerebral artery, M1 segment of the left middle cerebral artery and the entire left posterior cerebral artery. Vascular "beading" was also present in this distribution. The left thalamostriate vessels were more prominent when compared to the right side (Figure 1).

Routine laboratory values were within reference ranges. There were no abnormalities from viral titres; cultures; metabolic screens, including the thermolabile 5,10-methylenetetrahydrofolate reductase variant and homocysteine levels; C3 and C4 levels; antinuclear, anti-DNA and anticardiolipin antibodies; antinuclear cytoplasmic antibody screens, including myeloperoxidase cytoplasmic enzyme; or coagulation studies. Carotid sonogram (left carotid and vertebral arteries) revealed no evidence of dissection. She remained stable until 60 hours after admission when she deteriorated suddenly and failed to respond to ventilation, mannitol and steroids. She was declared brain dead and removed from ventilatory support.

After autopsy, brain examination showed that the cerebrum was swollen and the cerebellar tonsils were herniated. The arteries at the base
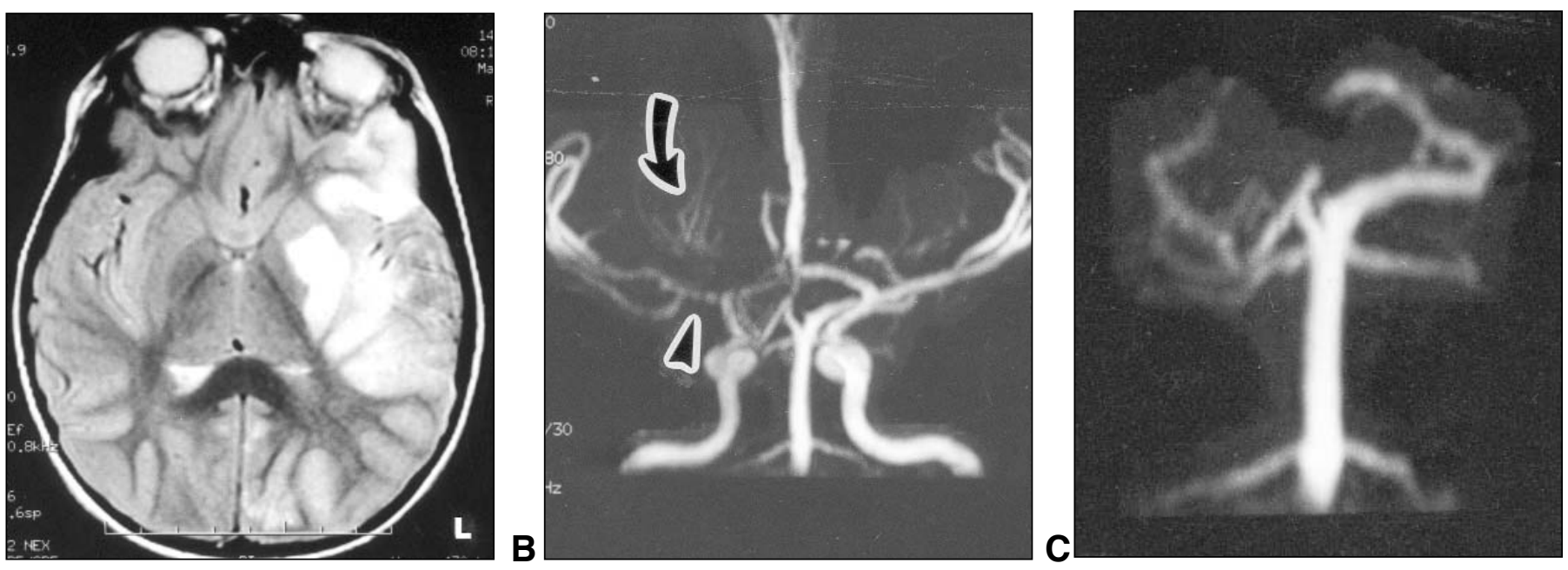

Figure 1: A - T2-weighted axial MR imaging shows high signal intensity of entire left cerebral hemisphere and basal ganglia. L = left. B - Frontal view of circle of Willis using MR angiography shows vascular narrowing and beading of supraclinoid left internal carotid and left posterior cerebral arteries, and M1 segment of left middle cerebral artery (arrowhead). Note prominent left thalamostriate vessels (curved arrow). C - Frontal view of posterior circulation with MR angiography show vascular narrowing and beading of left posterior cerebral artery. 

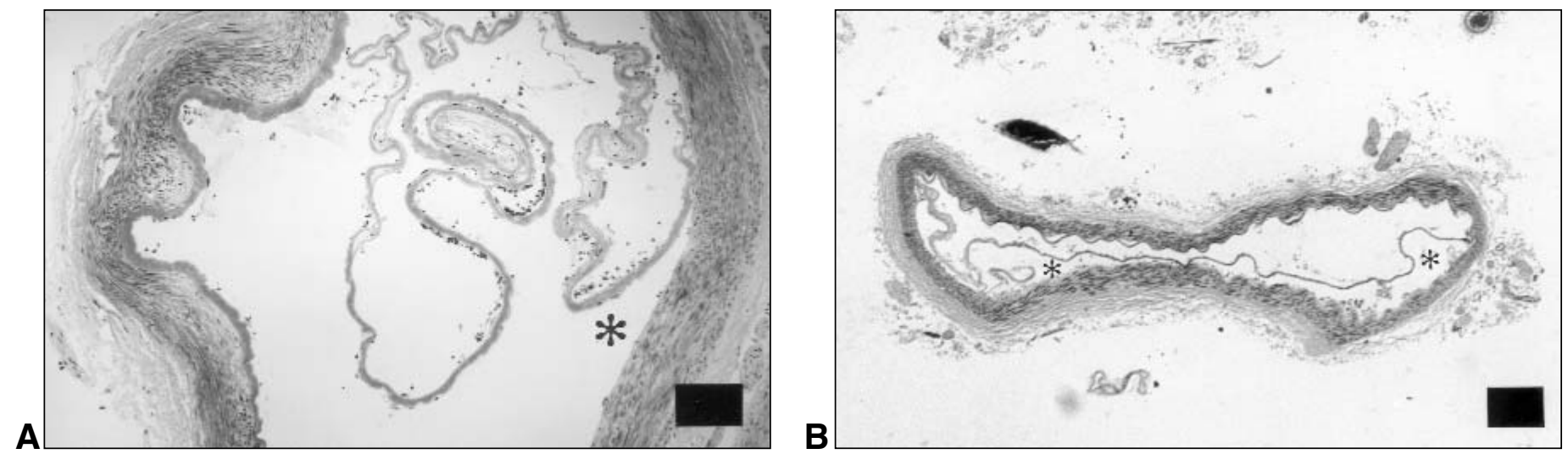

Figure 2: H\&E-stained sections of left $(A)$ and right $(B)$ proximal supraclinoid internal carotid arteries show partial dissection of the internal elastic lamina from the media, leaving a space between the mural layers (*). The elastica is ruptured with free ends curled in the lumen. A, bar = 100 um; B, bar $=300 \mu \mathrm{m}$.

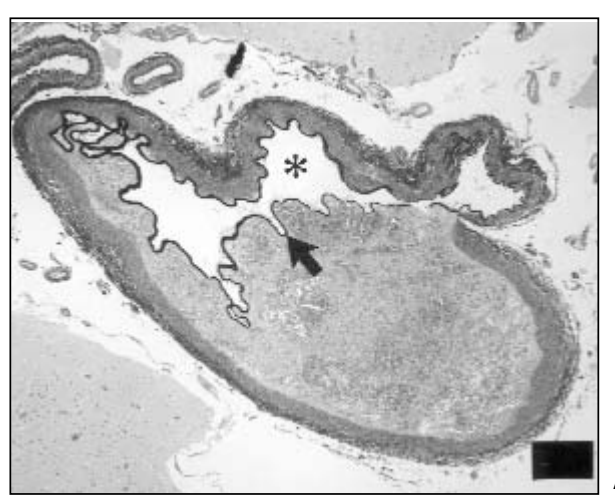

Figure 3: Elastin-stained section of subintimal dissecting hematoma of supraclinoid left internal carotid artery distal to the segment shown in Figure 2A. The hematoma separates the elastica (arrow) from the media, leaving a restricted luminal opening (*). Bar $=250 \mu \mathrm{m}$.
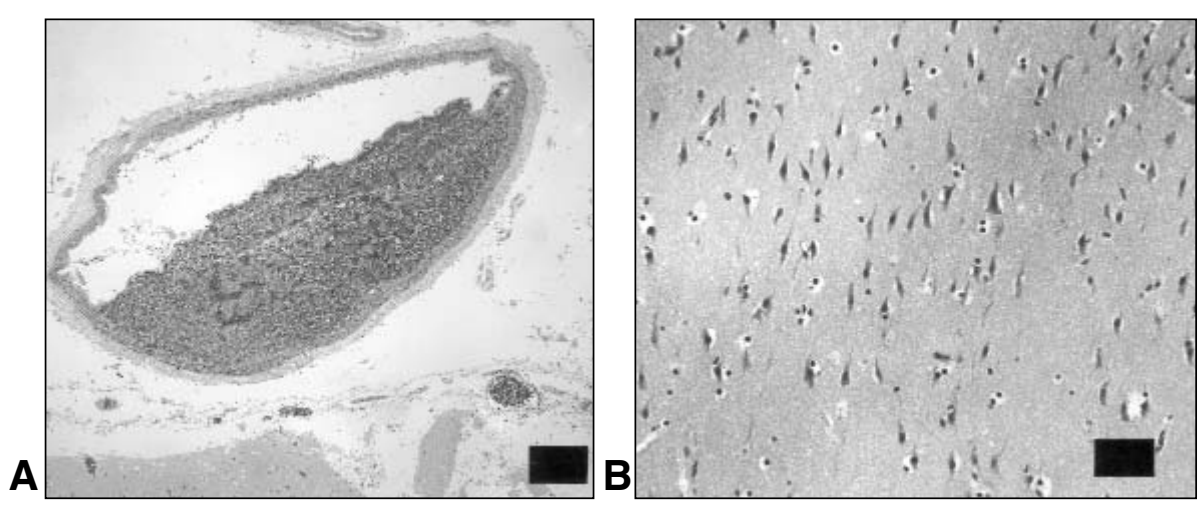

Figure 4: $A-H \& E$-stained section of left posterior cerebral artery with dissecting hematoma. $B$ - Infarcted left occipital cortex has shrunken neurons (H\&E stain). A, bar $=250 \mu \mathrm{m} ; \mathrm{B}$, bar $=$ $100 \mu \mathrm{m}$.
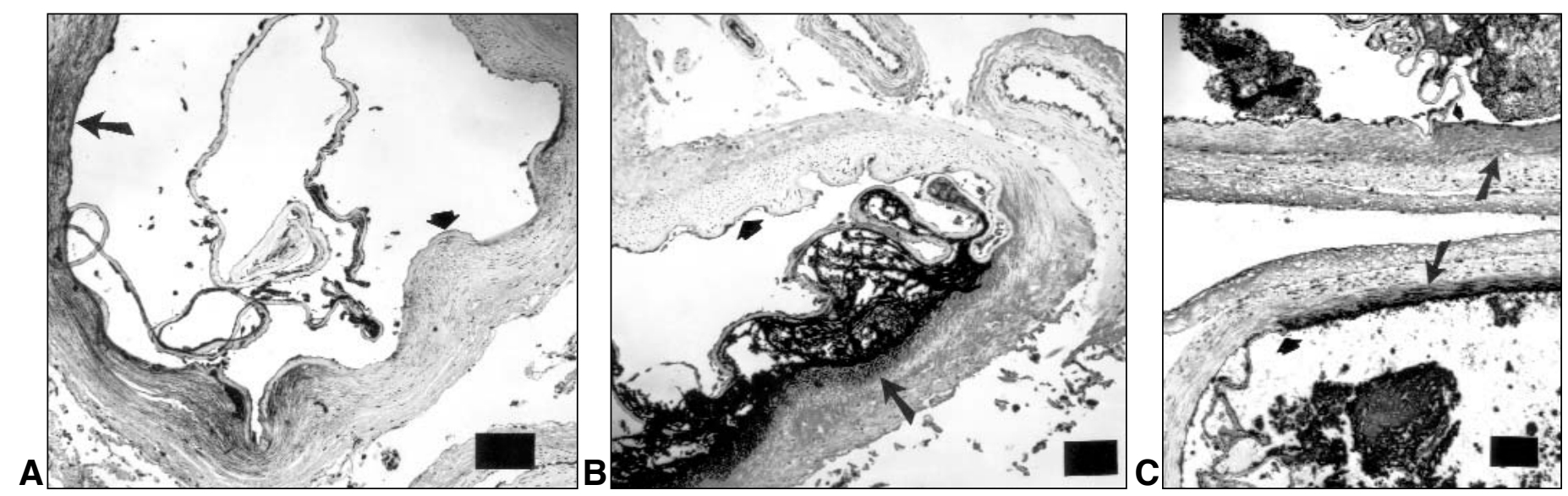

Figure 5: A - Proximal supraclinoid left internal carotid artery immunostained for IgM with deposition of IgM in media (long arrow) and on elastica where subintimal dissection has occurred. Media is mostly negative for IgM where the elastica remains attached (short arrowhead). B - Distal to A, subintimal hematoma is heavily IgM-immunoreactive. The media beneath the hematoma is also heavily immunostained for IgM, giving a stippled appearance (long arrow), but the medial layer beneath attached elastica is negative (short arrowhead). C - Two adjacent branches of the left middle cerebral artery have medial layer IgM immunoreactivity of varying intensity under subintimal hematomas (long arrows). Short arrowheads mark points of dissection of elastica from media. Bar $=100 \mu \mathrm{m}$. 
of the brain were congested and they had a normal configuration. Coronal sections of cerebrum revealed softened tissue and a distinct corticomedullary junction. No deep white matter or cortical changes were seen, but the lateral ventricles were small and the anterior horns were almost closed. There was a small anterior shift of midline structures from left to right. The superior aspect of the cerebellum was narrowed from supratentorial pressure along the tentorium cerebelli and the upper midbrain was slightly narrowed. No intraventricular hemorrhage was present. The caudal half of the medulla near the herniations had subarachnoid hemorrhage around it.

Microscopically, a subtotal subintimal dissection between the internal elastic lamina and the muscular medial layer was found in the right and left internal carotid arteries in their proximal portions that had been in an immediately supraclinoid position. The internal elastic lamina of the supraclinoid segment of both the left and right internal carotid arteries was ruptured and the broken ends were curled up in the lumen (Figure 2). An extensive dissecting hematoma involved the left internal carotid artery several millimetres distal to the supraclinoid subintimal dissection (Figure 3). The subintimal hematoma dissected into the left middle, anterior and posterior cerebral arteries in each of several sections made of these vessels. Each microscopic section had the same histologic appearance with blood between the elevated elastica and the otherwise normal-appearing media (Figure 4). The subintimal hematomas compromised the lumen by up to $80 \%$, while $40-70 \%$ of the circumferential extent of the elastica was dissected away from the media. There was a recent thrombus in the right anterior cerebral artery, and a proximal segment of the right middle cerebral artery had a scalloped appearance of the elastica that seemed to represent early separation from the media. No hematoma was found in the right internal carotid artery system. No medial degenerative findings were observed in any vessels. Basilar and intracranial vertebral arteries and all major neck vessels were normal. Recent infarcts were seen in the left frontal and occipital lobes (Figure 4B) and in Sommer's sector on the left.

Immunostains for IgG (rabbit polyclonal antibody, 1:2000, trypsin predigestion; DAKO, Denmark) showed heavy infiltration of infarcted cerebral tissue and moderately heavy immunolabeling of the entire medial layer of all of the major branches of the circle of Willis. IgM immunostaining (monoclonal antibody, 1:30, trypsin predigestion; DAKO) of each section containing the left intracranial internal carotid artery system showed a distinct staining pattern in most of the arterial segments with little or no IgM in the part of the arterial wall circumference that was intact, but with patchy to almost homogeneous IgM deposition in the medial layer adjacent to the subintimal dissections. IgM staining included the left internal carotid artery supraclinoid segments where no hematoma was found as well as the media adjacent to the hematoma (Figure 5). None of the normal arterial branches had IgM deposition. IgA immunoreactivity (monoclonal antibody, 1:20, microwave antigen retrieval; DAKO) was negative. Immunoreactivity for fixed complement component C3 (monoclonal antibody, 1:100, trypsin predigestion; DAKO) was equivocally present in the medial layer of arteries with dissections, while normal-appearing arteries were negative.

\section{REVIEW OF THE LITERATURE AND CURRENT FINDINGS}

The 41 cases with intracranial internal carotid artery system dissecting hematomas studied histologically in previous publications, with the addition of the present case, average 17.5 years of age at presentation. The only long-term survivors include three patients with onset at one year of age or younger. ${ }^{2-}$ ${ }^{4}$ Of the 42 total cases, 18 had trauma, including 10 with mild or trivial head trauma, while 10 had physical exertion, two had migraines, and one had emotional exertion. These cases include two instances with both mild trauma and physical exertion relatively closely related to rapid collapse. The most common dissecting hematoma of limited extent is of the right (nine cases) or left (eight cases) middle cerebral arteries alone, although middle cerebral artery dissection is found in $37 / 42$ patients. Internal carotid artery dissection is present in $21 / 42$ cases, with the intramural hematoma continuing into the middle and anterior cerebral arteries in 3/42 cases. A left anterior cerebral artery is dissected alone in $1 / 42$ cases. Bilateral dissections in 2/42 cases involve the internal carotid and middle cerebral arteries and another bilateral case has in addition anterior cerebral artery dissections on both sides. One case has an extensive dissecting hematoma of the right internal carotid, middle, anterior and posterior cerebral arteries. Our case has a similarly extensive dissecting hematoma of the left internal carotid artery system and an early separation of the right internal carotid and middle cerebral artery intimal layer from the media. The posterior cerebral artery has not been involved alone in cases with histologic data (Table).

\section{Discussion}

Frequent causes of ischemic stroke in young adults include extracranial arterial dissection, cardioembolism, premature atherosclerosis, migraine, and hematologic and immunologic disorders, as well as drug abuse, primary angiitis of the central nervous system, connective tissue disorders, mitochondrial cytopathies and cerebral autosomal dominant arteriopathy. ${ }^{52}$ Dissecting hematomas appear to be a relatively common cause of extracranial internal carotid artery obstruction ${ }^{5,9,11,53}$ and of vertebrobasilar artery-related infratentorial infarcts. ${ }^{54}$ Intracranial arterial dissection is decidedly more uncommonly found than dissecting hematomas of neck vessels. Only histologically confirmed cases of intracranial internal carotid artery system dissection are compared here and these are fatal with the exception of the youngest patients. Fibromuscular dysplasia may be a rare cause of arterial dissection, ${ }^{40,55}$ although most cases of intracranial arterial dissection that invoke this disease may be showing only focal arterial healing. ${ }^{20}$

Radiologic identification of patients, such as by the "pearland-string" sign of beading in anterior ${ }^{56}$ and rarely in posterior branches of cerebral arteries, ${ }^{57}$ is important in diagnosis. However, whether cases of intracranial arterial dissection with known histology differ pathologically from surviving cases studied by radiologic imaging methods is not clear.,56-60 Therapy provided to survivors has included resection with or without a bypass procedure, ${ }^{60}$ occlusion, entrapment, wrapping, endovascular embolization, ${ }^{56}$ balloons, and detachable coils. ${ }^{58}$ Angioplasty and stents may hold promise ${ }^{58}$ but relatively few cases are on record and treatment avenues require further consideration. ${ }^{59}$ The rationale for anticoagulation in these patients is empirical. Rapid recognition and intervention are probably the keys to a successful outcome.

In our patient, the right internal carotid and middle cerebral arteries appear to be undergoing separation of the intimal layer with no intramural hematoma or significant compromise of the lumen. This could be an early event leading to a delayed hematoma or even to recovery when a significant hematoma does not form. Such a pathologic progression might be a cause of delay in symptoms, and it might also provide the degree of 
Table: Intracranial Carotid Artery System Dissecting Hematomas with Histologic Findings

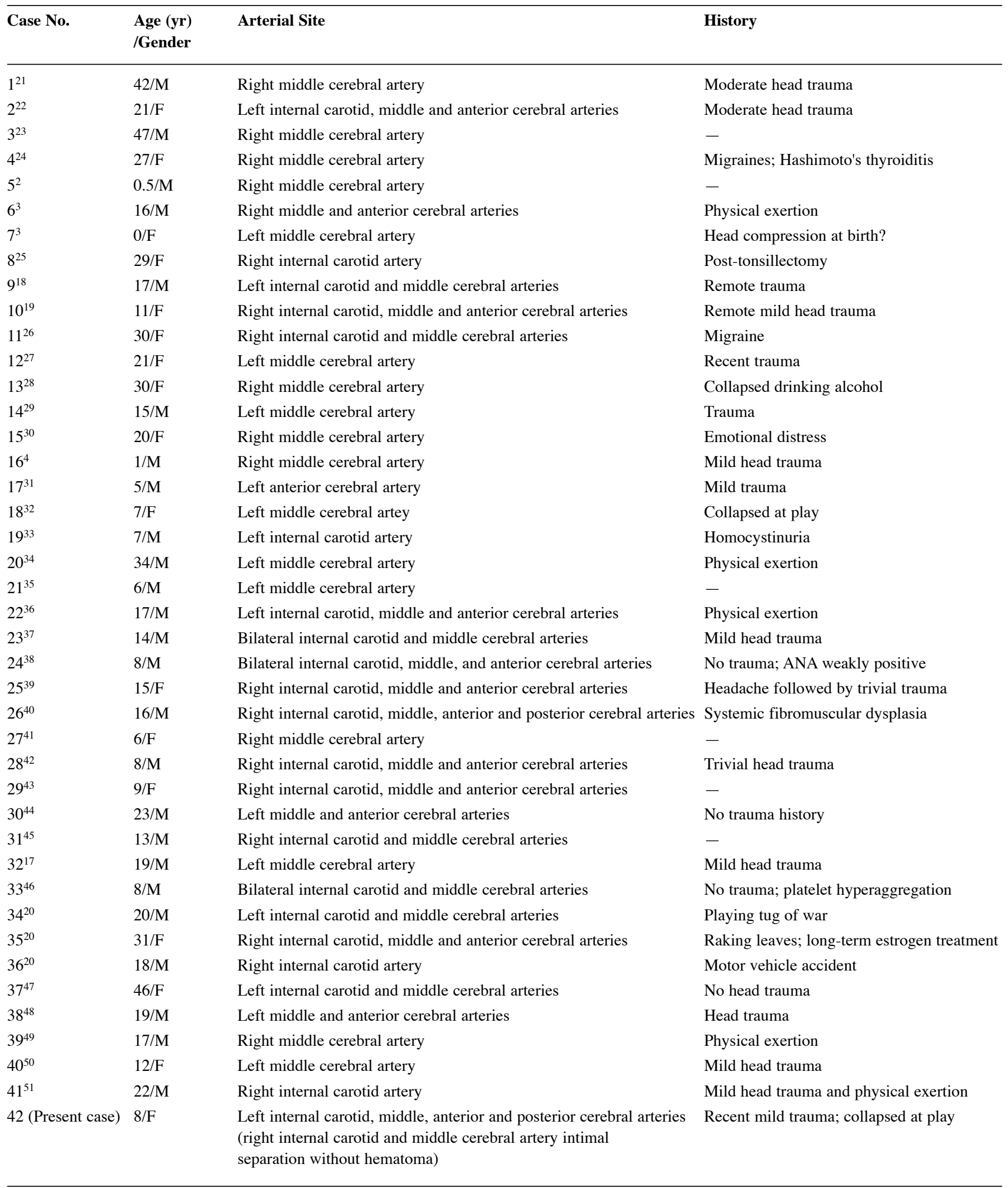

ANA = antinuclear antibody. 
severity of luminal closure that could be an important difference between surviving and autopsied cases.

Intramural dissections of the intracranial internal carotid artery system are generally thought to arise when normal gaps in the internal elastic lamina are altered by episodic hypertension. ${ }^{20}$ Sudden stretching from acutely increased blood pressure during trauma or exertion is thought to cause enlargement of the openings in the honeycomb structure of the elastica at proximal bifurcations..$^{20,61,62}$ It is speculated here that the anatomic site of the initial elastica disruption is related to tethering of the supraclinoid internal carotid artery at the anterior clinoid process. The supraclinoid segment and its middle and anterior cerebral artery branches are mobile, ${ }^{63}$ and the cardiac cycle would cause sudden lengthening and an abrupt recoil of these arterial branches. Systolic pressure at bifurcations flattens the apical tissue situated between the two daughter channels ${ }^{64}$ and sequential systolic flattening and diastolic narrowing cause maximal stress at these apical regions. ${ }^{65}$ Cerebral artery bifurcations are optimized to avoid such hemodynamic stress ${ }^{66}$ and arteriosclerotic lesions accumulated at bifurcations with age may play a protective role that further prevents arterial dissections after early middle age. ${ }^{67}$ In fact, the thickness of intimal pads at bifurcations increases during childhood and early adulthood and it reaches its greatest thickness at middle age. ${ }^{68}$ This may leave younger people less protected at proximal bifurcations. It may be that raised blood pressure flowing against a maturing but still thin intimal pad not too distant from the tethered proximal supraclinoid internal carotid artery helps to dislodge the intimal layer over the internal elastic lamina as the arterial system is translocated longitudinally and vertically during each cardiac cycle. Tethering at the anterior clinoid process might therefore translate high stress-strain forces maximally to initial branches of the intracranial internal carotid artery, aiding in damage to the intima and honeycomb structure. Significant damage to the endothelium and elastica appears to be rapidly amplified into a clinically significant breach of the internal elastic lamina. The elastica network appears to be sufficiently strong but its openings are large enough to admit blood cells into the subintimal layer should the endothelial layer become torn. ${ }^{62}$ Thus, as blood pressure increases, a small tear in the endothelium over the stretching elastica may admit subintimal blood and the elastica itself may tear, as is sometimes found histologically. The breach then becomes symptomatic over minutes to days as the subintimal dissection of blood forces an initially short segment of the arterial lumen shut. The initial breach need not be at a bifurcation, but that it involves only the elastica may be explained by the relative fragility of the internal elastic lamina compared to the media and adventitia under tensile extension of the arterial wall. ${ }^{69}$ The relatively proximal location of most intracranial dissections is consistent with this mechanism. The clinical severity may depend in part on the extent of dissection, although other factors that would be critical include the rapidity of cerebral edema formation, the rate of intracranial pressure increase that may lead to vascular collapse, and any associated vasculopathy such as medial degeneration or homocystinuria. Severe vasospasm during migraines may play a similar role.

Our patient experienced such an extensive dissection of the vascular system that consideration of its magnitude is in order.
One speculative mechanism of exacerbation of arterial wall damage involves pre-existing inflammatory disease. Vella et al ${ }^{70}$ report an 8-year-old girl with neck trauma followed by radiologic evidence of an aneurysm developing in a cervical internal carotid artery in association with circulating antibodies to antiprotease 3 . Case 24 in the Table, with bilateral subintimal dissecting hematomas of the intracranial internal carotid arteries, has a weakly positive serum antinuclear factor. ${ }^{38}$ Cystic medial necrosis as the cause of a focal dissecting hematoma of an internal carotid artery in case 41 is associated with an elevated leukocyte elastase content at the lesion site that may have been related to arterial damage. ${ }^{51}$ Case 4 has autoimmune thyroiditis. ${ }^{24}$ These findings suggest a possible place for humoral as well as for cellular mechanisms to influence the initiation or enlargement of dissecting mural hematomas.

A possible humoral influence is from preformed autoantibodies to normally hidden mural antigens. For example, rare individuals, with preformed antibodies to their cerebral artery walls, are found in primary angiitis of the central nervous system. These patients have a variety of comorbidity factors, the most common being a previous viral infection with supposed molecular mimicry being responsible for autoimmunity. ${ }^{71}$ An analogous mechanism could explain the acute reactivity of $\operatorname{IgM}$ in the subintimal muscle layer preferentially where the elastica has been lifted off. Although the initial mechanical dissection should be all that is required to cause severe clinical problems, we speculate that extensive subintimal dissections may require additional factors. Thus, cases with limited mural dissection might have only mechanical subintimal pad damage while very rare patients with an extensive dissection could have underlying autoimmunity as one potential factor in their lesion. For example, Thal et $\mathrm{al}^{51}$ found no immunoglobulin immunoreactivity in a short supraclinoid dissecting hematoma that did not extend far into the middle cerebral artery in case 41 , while in our patient the extensive dissection is associated with an apparent immunopathologic event.

In support of such mechanisms of vascular damage, autoantibodies and fixed complement components have been localized on subintimal and medial smooth muscle elastic microfibrils. ${ }^{72}$ In addition, reactivity for $\operatorname{IgM}$ and $\mathrm{C} 3$ in intracranial arterial aneurysms has been demonstrated after subarachnoid hemorrhage, ${ }^{73}$ while circulating immune complexes and raised plasma C3 levels are found with postrupture vasospasm. ${ }^{74}$ The relatively selective localization of IgM present in our case appears in the proximal vessels bilaterally, where no underlying hematoma is seen, as well as distally and it is deposited where vascular damage is most pronounced. Heavy IgG deposition is probably reflective of generalized tissue damage associated with infarction, ${ }^{75}$ while $\operatorname{IgA}$ staining serves as a negative staining control.

Vascular damage, including subintimal dissolution, might progress relatively rapidly, and most likely independently, by a second humoral mechanism. Arterial smooth muscle cells under high in vitro shear stress, ${ }^{76}$ or with the influence of plasma thrombin, elaborate significant amounts of tissue plasminogen activator, and plasmin depolymerizes vascular smooth muscle elastic fibrils within a few hours. ${ }^{77}$ Thrombin might have other direct actions causing vasospasm ${ }^{78}$ and complement activation after it is activated by exposed vascular smooth muscle cells. ${ }^{79-81}$ 
Such immune reactivity in vascular damage, including immune complexes and complement in intracranial saccular aneurysms, ${ }^{73,74}$ may play a role in beading and stenosis observed radiologically and simulating vasculitis ${ }^{6}$ as well as in enlarging a mechanical dissection.

\section{ACKNOWLEDGEMENTS}

We thank Mrs. Sharon Allen, Mrs. Susan Janeczko and Ms. Vicki Brown for excellent technical assistance. Mr. Gary Burgess provided photographic assistance. Supported in part by the University of Manitoba Department of Pathology Research Donations Fund.

\section{REFERENCES}

1. Poppen JL. Specific treatment of intracranial aneurysms: experience with 143 surgically treated patients. J Neurosurg 1951; 8: 75-102.

2. Norman RM, Urich H. Dissecting aneurysm of the middle cerebral artery as a cause of acute infantile hemiplegia. J Pathol Bacteriol 1957; 73: 580-582.

3. Wolman L. Cerebral dissecting aneurysms. Brain 1959; 82: 276291.

4. Shillito J Jr. Carotid arteritis: a cause of hemiplegia in childhood. J Neurosurg 1964; 21: 540-551.

5. Fisher CM, Ojemann RG, Roberson GH. Spontaneous dissection of cervico-cerebral arteries. Can J Neurol Sci 1978; 5: 9-19.

6. Hart RG, Easton JD. Dissections of cervical and cerebral arteries. Neurol Clin 1983; 1: 155-182.

7. Schievink WI, Mokri B, Piepgras DG. Spontaneous dissections of cervicocephalic arteries in childhood and adolescence. Neurology 1994; 44: 1607-1612.

8. Patel H, Smith RR, Garg BP. Spontaneous extracranial carotid artery dissection in children. Pediatr Neurol 1995; 13: 55-60.

9. Sturzenegger M. Spontaneous internal carotid artery dissection: early diagnosis and management in 44 patients. J Neurol 1995; 242: 231-238

10. Provenzale JM, Barboriak DP. Brain infarction in young adults: etiology and imaging findings. AJR Am J Roentgenol 1997; 169: 1161-1168

11. Guillon B, Lévy C, Brousser M-G. Internal carotid artery dissection: an update. J Neurol Sci 1998; 153: 146-158.

12. DeBehnke DJ, Brady W. Vertebral artery dissection due to minor neck trauma. J Emerg Med 1994; 12: 27-31.

13. Sagoh M, Hirose Y, Murakami H, et al. Cerebellar infarction with hydrocephalus caused by spontaneous extracranial vertebral artery dissection - case report. Neurol Med Chir (Tokyo) 1997; 37: $538-541$

14. Friedman AH, Drake CG. Subarachnoid hemorrhage from intracranial dissecting aneurysm. J Neurosurg 1984; 60: 325-334.

15. Mizutani T, Aruga T, Kirino T, et al. Recurrent subarachnoid hemorrhage from untreated ruptured vertebrobasilar dissecting aneurysms. Neurosurgery 1995; 36: 905-911.

16. Yasui T, Komiyama M, Nishikawa M, Nakajima H. Subarachnoid hemorrhage from vertebral artery dissecting aneurysms involving the origin of the posteroinferior cerebellar artery: report of two cases and review of the literature. Neurosurgery 2000; 46: 196200.

17. Mizutani T, Goldberg HI, Parr J, Harper C, Thompson CJ. Cerebral dissecting aneurysm and intimal fibroelastic thickening of cerebral arteries: case report. J Neurosurg 1982; 56: 571-576.

18. Ritchie G. Dissecting aneurysm of the left internal carotid and left middle cerebral arteries. Report of a case. Wis Med J 1961; 60: 556-558.

19. Wisoff HS, Rothballer AB. Cerebal arterial thrombosis in children. Review of literature and addition of two cases in apparently healthy children. Arch Neurol 1961; 4: 258-267.

20. Farrell MA, Gilbert JJ, Kaufmann JCE. Fatal intracranial arterial dissection: clinical pathological correlation. J Neurol Neurosurg Psychiatry 1985; 48: 111-121.

21. deVeer JA, Browder J. Post-traumatic cerebral thrombosis and infarction. Report of a case and discussion on its bearing on the problem of immediate and delayed post-traumatic apoplexy. $\mathbf{J}$ Neuropathol Exp Neurol 1942; 1: 24-31.

22. Dratz HM, Woodhall B. Traumatic dissecting aneurysm of left internal carotid, anterior cerebral and middle cerebral arteries. J Neuropathol Exp Neurol 1947; 6: 286-291.

23. Ramsey TL, Mosquera VT. Dissecting aneurysm of the middle cerebral artery. Ohio Med J 1948; 44: 168-170.

24. Sinclair W Jr. Dissecting aneurysm of the middle cerebral artery associated with migraine syndrome. Am J Pathol 1953; 29: 10831091

25. Scott GE, Neuberger KT, Denst J. Dissecting aneurysm of the intracranial arteries. Neurology 1960; 10: 22-27.

26. Spudis EV, Scharyj M, Alexander E, et al. Dissecting aneurysms in the neck and head. Neurology 1962; 12: 867-875.

27. Duman S, Stephens JW. Post-traumatic middle cerebral artery occlusion. Neurology 1963; 13: 613-616.

28. Nedwich A, Haft H, Tellem M, Kauffman L. Dissecting aneurysm of cerebral arteries. Review of the literature and report of a case. Arch Neurol 1963; 9: 477-484.

29. Dourov N, Locoge M, Themelin G, deRede J. Étude anatomoclinique et radiologic d'un cas d'hématome disséquant d'une artère cérébral chez un sujet jeune. Rev Belg Path 1964; 30: 265281.

30. Robert F, Maltais R, Giroux JC. Dissecting aneurysm of middle cerebral artery: case report. J Neurosurg 1964; 21: 413-415.

31. Nelson JW. Dissecting subintimal hematomas of the intracranial arteries: report of a case. J Am Osteopath Assn 1968; 67: 512517.

32. Jacob JC, Maroun FB, Heneghan WD, House AM. Uncommon cerebrovascular lesions in children. Dev Med Child Neurol 1970; 12: 446-453.

33. Isler W. Acute hemiplegias and hemisyndromes in childhood. Clin Dev Med 1971;41/42: 28-30.

34. Kunze S, Schiefer W. Angiographic demonstration of a dissecting aneurysm of the middle cerebral artery. Neuroradiology 1971; 2: 201-206.

35. Sato O, Bascom JF, Logothetis J. Intracranial dissecting aneurysm. Case report. J Neurosurg 1971; 35: 483-487.

36. Pikula B, Plamenac P, Ferkovic M. Anévrisme disséquant (hématome disséquant) d'une artère cérébrale après un effort physique intense. Rev Neurol 1973; 128: 125-130.

37. Adelman LS, Doe FD, Sarnat HB. Bilateral dissecting aneurysms of the internal carotid arteries. Acta Neuropathol (Berl) 1974; 29: 93-97.

38. Chang V, Rewcastle NB, Harwood-Nash DCF, Norman MG. Bilateral dissecting aneurysms of the intracranial internal carotid arteries in an 8-year-old boy. Neurology 1975; 25: 573-579.

39. Hochberg FH, Bean C, Fisher CM, Roberson GH. Stroke in a 15year-old girl secondary to terminal carotid dissection. Neurology 1975; 25: 725-729.

40. Pilz P, Hartjes HJ. Fibromuscular dysplasia and multiple dissecting aneurysms of intracranial arteries. A further cause of Moyamoya syndrome. Stroke 1976; 7: 393-398.

41. Gagne F, LeMay M, Verret S. Hémodissection pariétale oblitérante des vaisseaux intracrâniens, une forme particulière d'anévrysme disséquant. Can J Neurol Sci 1977; 4: 63-65.

42. Johnson AC, Graves VB, Pfaff JP Jr. Dissecting aneurysms of intracranial arteries. Surg Neurol 1977; 7: 49-52.

43. Manz HJ, Vester J, Lavenstein B. Dissecting aneurysm of cerebral arteries in childhood and adolescence. Case report and literature review of 20 cases. Virchows Arch A Pathol Anat Histol 1979; 384: $325-335$.

44. Grosman H, Fornasier VL, Bonder D, Livingston KE, Platts ME. Dissecting aneurysm of the cerebral arteries: case report. J Neurosurg 1980; 53: 693-697.

45. Hegedus K. Dissecting intracranial aneurysm. Arch Psychiatr Nervenkr 1982; 232: 25-32.

46. Nass R, Hays A, Chutorian A. Intracranial dissecting aneurysms in childhood. Stroke 1982; 13: 204-207.

47. Pessin MS, Adelman LS, Barbas NR. Spontaneous intracranial carotid artery dissection. Stroke 1989; 20: 1100-1103.

48. Schmitt HP, Miltner E. Dissection of the anterior and middle 
cerebral artery with fatal ischemia following kicks to the head. Forensic Sci Int 1991; 49: 113-120.

49. Sharif AA, Remley KB, Clark HB. Middle cerebral artery dissection: a clinicopathologic study. Neurology 1995; 45: 19291931.

50. Adams C, Trevenen C. Middle cerebral artery dissection. Neuropediatrics 1996; 27: 331-332.

51. Thal DR, Schober R, Schlote W. Carotid artery dissection in a young adult: cystic medial necrosis associated with an increased elastase content. Clin Neuropathol 1997; 16: 180-184.

52. Martin PJ, Enevoldson TP, Humphrey PR. Causes of ischaemic stroke in the young. Postgrad Med J 1997; 73: 8-16.

53. Hilton-Jones D, Warlow CP. Non-penetrating arterial trauma and cerebral infarction in the young. Lancet 1985; 1: 1435-1438.

54. Malm J, Kristensen B, Carlberg B, Fagerlund M, Olsson T. Clinical features and prognosis in young adults with infratentorial infarcts. Cerebrovasc Dis 1999; 9: 282-289.

55. Sato S, Hata J. Fibromuscular dysplasia. Its occurrence with a dissecting aneurysm of the internal carotid artery. Arch Pathol Lab Med 1982; 106: 332-335.

56. Yamaura A, Ono J, Hirai S. Clinical picture of intracranial nontraumatic dissecting aneurysm. Neuropathology 2000; 20: 85-90.

57. Lazinski D, Willinsky RA, TerBrugge K, Montanera W. Dissecting aneurysms of the posterior cerebral artery: angioarchitecture and a review of the literature. Neuroradiology 2000; 42: 128-133.

58. Hemphill JC 3rd, Gress DR, Halbach VV. Endovascular therapy of traumatic injuries of the intracranial cerebral arteries. Crit Care Clin 1999; 15: 811-829.

59. Silverboard G, Tart R. Cerebrovascular arterial dissection in children and young adults. Semin Pediatr Neurol 2000; 7: 289300 .

60. Wakabayashi $\mathrm{Y}$, Nakano $\mathrm{T}$, Isono $\mathrm{M}$, Shimomura $\mathrm{T}$, Hori $\mathrm{S}$. Dissecting aneurysm of the anterior cerebral artery requiring surgical treatment-case report. Neurol Med Chir (Tokyo) 2000; 40: 624-627.

61. Campbell GJ, Eng P, Roach MR. Fenestrations in the internal elastic lamina at bifurcations of human cerebral arteries. Stroke 1981; 12: 489-500.

62. Yamazoe N, Hashimoto N, Kikuchi H, et al. Study of the elastic skeleton of intracranial arteries in animal and human vessels by scanning electron microscopy. Stroke 1990; 21: 765-770.

63. Carpenter MB. Human Neuroanatomy, 7th ed. Baltimore: Williams \& Wilkins Co., 1976, pp. 603-605.

64. Roach MR. The structure and elastic properties of arterial junctions. Connect Tissue Res 1986; 15: 77-84.

65. MacFarlane TWR, Roach MR, Chan K. The geometry of human cerebral bifurcations: effect of static distending pressure. J Biomech 1980; 13: 265-277.

66. Rossitti S, Lofgren J. Optimality principles and flow orderliness at the branching points of cerebral arteries. Stroke 1993; 24: 10291032.

67. Sakata N, Joshita T, Ooneda G. Topographical study on arteriosclerotic lesions at the bifurcations of human cerebral arteries. Heart Vessels 1985; 1: 70-73.

68. Klassen AC, Sung JH, Stadlan EM. Histological changes in cerebral arteries with increasing age. J Neuropathol Exp Neurol 1968; 27: 607-623.

69. Broom ND, Ramsey G, Mackie R, Martin BJ, Stehbens WE. A new biomechanical approach to assessing the fragility of the internal elastic lamina of the arterial wall. Connect Tissue Res 1993; 30: 143-155.

70. Vella S, Ramelli GP, Schroth G, Bianchetti MG. Circulating antineutrophil autoantibodies in a child with isolated central nervous system vasculitis. Neuropediatrics 1999; 30: 268-269.

71. Rhodes RH, Madelaire NC, Petrelli M, Cole M, Karaman BA. Primary angiitis and angiopathy of the central nervous system and their relationship to systemic giant cell arteritis. Arch Pathol Lab Med 1995; 119: 334-349.

72. Helin H, Matila J, Rantala I, Vaalasti T. In vivo binding of immunoglobulin and complement to elastic structures in urinary bladder vascular walls in interstitial cystitis: demonstration by immunoelectron microscopy. Clin Immunol Immunopathol 1987; 43: 88-96.

73. Ryba M, Jarzabek-Chorzelska M, Chorzelski T, Pastuszko M. Is vascular angiopathy following intracranial aneurysm rupture immunologically mediated? Acta Neurochir (Wien) 1992; 117: 34-37.

74. Ostergaard JR, Kristensen BO, Svehag SE, Teisner B, Miletic T. Immune complexes and complement activation following rupture of intracranial saccular aneurysms. J Neurosurg 1987; 66: 891897.

75. Rhodes RH. Evidence of serum-protein leakage across the bloodbrain barrier in the acquired immunodeficiency syndrome. J Neuropathol Exp Neurol 1991; 50: 171-183.

76. Papadaki M, Ruef J, Nguyen KT, et al. Differential regulation of protease activated receptor- 1 and tissue plasminogen activator expression by shear stress in vascular smooth muscle cells. Circ Res 1998; 83: 1027-1034.

77. Okada H, Nordt T, Lundgren CH, Fujii S. Human aortic vascular smooth muscle cells digest extracellular matrix by elaboration of plasminogen activators: implications for atherogenesis. J Thromb Thrombolysis 1995; 2: 107-112.

78. Jerius H, Beall A, Woodrum D, Epstein A, Brophy C. Thrombininduced vasospasm: cellular signaling mechanisms. Surgery 1998; 123: 46-50.

79. Dennington PM, Berndt MC. The thrombin receptor. Clin Exp Pharmacol Physiol 1994; 21: 349-358

80. Wilcox JN, Rodriguez J, Subramanian R, et al. Characterization of thrombin receptor expression during vascular lesion formation. Circ Res 1994; 75: 1029-1038.

81. Benzakour O, Kanthou C, Lupu F, et al. Prothrombin cleavage by human vascular smooth muscle cells: a potential alternative pathway to the coagulation cascade. J Cell Biochem 1995; 59: 514-528. 